\title{
Solid-state cultures of Fusarium oxysporum transform aromatic components of olive-mill dry residue and reduce its phytotoxicity
}

\author{
Inmaculada Sampedro ${ }^{\text {a }}$, Alessandro D'Annibale ${ }^{\mathrm{b}}$, Juan A. Ocampo ${ }^{\text {a }}$, \\ Silvia R. Stazi ${ }^{\text {b }}$ Inmaculada García-Romera ${ }^{\text {a,* }}$ \\ a Departamento Microbiología, Estación Experimental del Zaidin, CSIC, Prof. Albareda 1, E-18008 Granada, Spain \\ ${ }^{\mathrm{b}}$ Dipartimento di Agrobiologia e Agrochimica, University of Tuscia, Via San Camillo de Lellis snc I-01100 Viterbo, Italy
}

Received 23 June 2006; received in revised form 13 November 2006; accepted 13 November 2006

Available online 4 January 2007

\begin{abstract}
The present study mainly investigated the ability of solid-state cultures of the non-pathogenic Fusarium oxysporum strain BAFC 738 to transform aromatic components to reduce the phytotoxicity in olive-mill dry residue (DOR), the waste from the two-phase manufacturing process. Lignin, hemicellulose, fats and water-soluble extractives contents of DOR colonized by the fungus for 20 weeks were reduced by $16 \%, 25 \%, 71 \%$ and $13 \%$, respectively, while the cellulose content increased by $25 \%$. In addition, the ethyl acetate-extractable phenolic fraction of the waste was reduced by $65 \%$. However, mass-balance ultra-filtration and size-exclusion chromatography experiments suggested that the apparent removal of that fraction, mainly including 2-(3,4-dihydroxyphenyl)ethyl alcohol and 2-(4-hydroxyphenyl)ethyl alcohol, was due to polymerization. Mn-peroxidase and Mn-independent peroxidase activities were found in $F$. oxysporum solid-state cultures, while laccase and aryl alcohol oxidase activities were not detected. Tests performed with seedlings of tomato ( $L y c o-$ persicum esculentum L.), soybean (Glycine maximum Merr.), and alfalfa (Medicago sativa L.) grown on soils containing 6\% (w/w) of bioconverted DOR ( $\mathrm{kg}$ soil) ${ }^{-1}$ showed that the waste's phytotoxicity was removed by 20 weeks-old fungal cultures. By contrast, the same material exhibited a high residual toxicity towards lettuce (Lactuca sativa L.).
\end{abstract}

(C) 2006 Elsevier Ltd. All rights reserved.

Keywords: Fusarium oxysporum; Dry olive-mill residue; Phenols; Phytotoxicity

\section{Introduction}

The olive oil industry has a significant environmental impact due to the production of huge amounts of either a highly polluted wastewater or a solid residue, depending on the olive oil extraction process. In the last two decades Spain, the greatest producer of olive oil at a worldwide level has witnessed the increasing replacement of the three-phase extraction process by the so-called two-phase system. The latter technology for olive oil extraction consists of a continuous centrifugation two-phase process that generates a liquid phase (olive oil) and a solid organic waste (alpeorujo), which is then dried and extracted with solvents

\footnotetext{
${ }^{*}$ Corresponding author. Tel.: +34 58181600x274; fax: +34 58129600 .

E-mail address: igarcia@eez.csic.es (I. García-Romera).
}

to obtain an extra yield of oil and a dry residue (DOR) (Vlyssides et al., 1998).

The two-phase extraction system yields about $800 \mathrm{~kg}$ of alpeorujo per ton of processed olives so that it has been calculated that the annual production of DOR in Spain approach four million tons (MAPA, 2002). Thus, the environmental risks associated with the production of huge amounts of DOR require the development of new technological procedures allowing a profitable and environmentally sound use of the waste.

One of the main drawbacks to the biological degradation and/or upgrading of olive-mill residues by either aerobic or anaerobic processes is due to the presence of phenols, which may occur both in monomeric (Capasso et al., 1992; Sampedro et al., 2004a) and polymeric form (Sayadi et al., 2000). In fact, polyphenols have been shown to be responsible for 